\title{
LA EXCLUSIÓN SOCIAL DEL HOMBRE RURAL DURANTE LA POSTGUERRA CIVIL ESPAÑOLA, A TRAVÉS DE LA NOVELA LAS RATAS DEL ESCRITOR MIGUEL DELIBES
}

\author{
Gracineia dos Santos Araújo ${ }^{1}$
}

Resumen: Durante la postguerra española, la exclusión social del hombre rural castellano consiste una de las principales preocupaciones del escritor Miguel Delibes. Ante esta realidad, marcada por los abismos sociales, el autor decide "salir a cuerpo abierto" en defensa del redimensionamiento de las políticas agrarias, destinadas al campo, otorgándole a su narrativa la misión de crítica y denuncia social. En esta perspectiva, y a partir de las vicisitudes de sus personajes, nace la novela Las ratas (1962) a través de la cual el autor elabora una imagen auténtica de las penurias del campesino español.

Palabras-clave: Miguel Delibes; Literatura española; Exclusión social.

Resumo: Durante o período do pós-guerra civil espanhola, a exclusão social do homem rural castelhano consiste em uma das principais preocupações do escritor Miguel Delibes. Diante desta realidade, marcada pelos abismos sociais, o autor decide "sair de corpo e alma" em defesa do redimensionamento das políticas agrárias, destinadas ao campo, outorgando a sua narrativa a missão de crítica e denúncia social. Nesta perspectiva, e a partir das vicissitudes dos seus personagens, nasce o romance Las ratas (1962), através do qual o autor elabora uma imagem autêntica das penúrias do homem rural castelhano.

Palavras-chave: Miguel Delibes; Literatura espanhola; Exclusão social.

\footnotetext{
${ }^{1}$ Doctoranda en Español: Lingüística, Literatura y Comunicación (Universidad de Valladolid España); Máster en Filología Hispánica por el Instituto de Lengua, Literatura y Antropología (Centro de Ciencias Humanas y Sociales, CSIC/Madrid-España (2008), Diploma de Estudios Avanzados en Literatura Española e Hispanoamericana-Universidad de Salamanca-España (2010). Licenciatura en Letras con español: especialidad en lengua española y portuguesa y sus respectivas literaturas. E-mail: gracineia@hotmail.com
} 


\section{INTRODUCCIÓN}

En el año 1962, el escritor vallisoletano Miguel Delibes publica la novela Las ratas tras haber sido prohibida una campaña en defensa del campo castellano. Surgida como forma de protesta, la obra brota de la pluma de un cazador-queescribe $^{2}$ como la más auténtica forma de denuncia social. A través de esta obra, el autor no solo muestra la cruda realidad de la vida en el campo castellano, sino que intenta reflejar la problemática individual y colectiva del hombre rural, señalando las disparatadas injusticias sociales que condenan a la mayoría de sus habitantes a la miseria y el hambre.

Se trata de una obra cuya intención didáctica y ética es muy fuerte, emergida de la denuncia y la ironía, lo que a veces parece acercar la narrativa a lo ridículo y a lo patético, dado el desenlace de sus historias, protagonizada por seres casi cavernícolas, como es el caso del tío Ratero, que se dedica a cazar ratas para asegurar la supervivencia. Además, no ve más allá del horizonte de sus necesidades básicas, le faltan las luces para cambiar el destino de su historia. Con actitudes y aspecto que bordean la comicidad, la realidad del protagonista provoca, incluso, efectos deprimentes, una vez que posee "sus dientes podridos" (Las ratas, p.11). Su realidad está repleta de historias que llegan a provocar compasión, lo que demuestra en la narrativa la complicidad del escritor con la vida, con el ser humano. Para Lozano (1993), estas historias tienen una dimensión ética muy amplia, ya que no son meros testigos o testimonios de un momento histórico, sino que cuestionan la sociedad y sus tradiciones.

La miseria y el hambre en el universo del Ratero parecen un mal necesario. Debido a ello, quizás, no hay ganas de progresar, de alcanzar la libertad; no hay sueño...lo que hay es el conformismo, la aceptación plena de la miseria. Hay un mundo que se resume en cazar ratas para sobrevivir, un mundo carente de consciencia, de inquietudes... poblado por unos individuos que no se dan cuenta

\footnotetext{
${ }^{2}$ Término utilizado por frecuentes titulares de diarios y revistas, en el año 1975, como consecuencia del nombramiento del escritor Miguel Delibes a la Real Academia Española, lo que señalaba, desde aquél entonces, la vocación campestre del escritor castellano.
} 
del retraso en que viven; un mundo de opresión e impotencia, de resignación y reduccionismo.

Las Ratas se desarrolla en un pueblo castellano, en una comunidad extremadamente cerrada, formada por unos habitantes aislados en su propio mundo. Dividido en diecisiete capítulos, esta obra tiene como protagonistas a Nini y al tío Ratero, quienes, aterrados y aferrados a la más sórdida realidad, son incapaces de cambiar el destino de sus vidas.

En Las Ratas, Miguel Delibes refleja los aspectos de la vida del mundo rural en una dimensión sumamente amplia, aportando un matiz social muy claro. A través de las formas de vida y costumbres, de los lugares...el autor problematiza la realidad e invita no solo a la reflexión, sino a tomar partido ante el abandono en que se encuentran las poblaciones rurales de la postguerra:

Esa captación del vivir de las gentes y los pueblos de Castilla en su realidad actual de cada día, esa adivinación de los sentimientos y pasiones que mueven el alma labriega y pueblerina, no tiene nada que ver con la idílica estampa de la vida rural reflejada en nuestras viejas novelas regionales y costumbristas, siempre dispuestas a encontrar el elogio del terruño y la alabanza de la aldea (VILANOVA, 1993, p.32).

Lejos de mostrar una visión idílica del mundo rural, Miguel Delibes aborda las desigualdades sociales que afligen al campesino con un lenguaje y preciso, que no da margen a dudas. Apoyado en sus ideas ecologistas, que caracterizan gran parte de sus narrativas de carácter rural, el escritor vallisoletano resalta y denuncia estas desigualdades existentes en el campo y la precariedad de la vida de sus habitantes; se apropia del mundo rural y lo hace como si fuera suyo, con una escritura dotada de una retranca ética sumamente peculiar. Según Lozano (1993, p.23):

El lenguaje delibiano es de las cosas más tranquilizadoras. Es un invento suyo, pero suena en cada momento al lenguaje exacto de cada cual, y al del lector, y el encantamiento funciona a la perfección; sólo más tarde, el lector de esas páginas "tan descansadas" se percata de que ha sido "envenenado" de algún modo.

Mientras el Ratero y el Nini viven en una cueva, pendiente de las adversidades del tiempo y de lo que va a comer... don Antero, el Poderoso, es dueño de grandes extensiones de tierras que se pierden en el horizonte. En este escenario, 
emprenden los protagonistas la lucha por la supervivencia, empezando muy temprano, como lo observamos en el fragmento a continuación:

Poco después del amanecer, el Nini se asomó a la boca de la cueva y contempló la nube de cuervos reunidos en concejo...

La perra se enredó en las piernas del niño y él le acarició el lomo a contrapelo, con el sucio pie desnudo, sin mirarla; luego bostezó, estiró los brazos y levantó los ojos al lejano cielo arrasado:

El tiempo se pone de helada, Fa. El domingo iremos a cazar ratas dijo (DELIBES, 2010, p.09).

Debido a estas circunstancias, de sórdidas desigualdades, Miguel Delibes encuentra el terreno fértil para lo que podríamos denominar "misión" en defensa del mundo rural. Todo ello, motivado por la consciencia de la existencia de una línea divisoria latifundista que separaba a ricos y pobres en el campo español, y por el anhelo de hacer realidad unos ideales como los proclamados por la Revolución Francesa, comprendidos en tres grandes valores: liberté, égalité, fraternité, subrayando el hecho de que "en España la Revolución Francesa todavía está inédita", además de añadir que "son dos siglos de retraso" (DELIBES apud DE LOS RíOS, 1993, p. 61).

Debido al componente ideológico de Delibes, defensor del mundo rural, como manifiesto de denuncia de las desigualdades e injusticias existentes en la vida lejos del progreso de la ciudad, se puede observar que el autor toma partido de la problemática existente. A través su ingeniosa imaginación literaria, basada en su propia experiencia como amante de la naturaleza y del contacto personal con los campos de su Castilla natal, como ciudadano comprometido con el medio ambiente, con las desigualdades sociales existentes, el autor recuerda:

Un día, caminando por tierras segovianas, sorprendí a un hombre que cazaba ratas en un arroyo para vendérselas a sus convecinos para su sustento. Este hombre me pareció un símbolo de la Castilla de entonces y lo erigí en el protagonista de mi novela - que escribí para resarcirme de la campaña de prensa que no pude hacer colocando a su lado a un niño sabio y generoso, el Nini, que bien pudiera representar el espíritu de Castilla, rico y esperanzado, en dramático contraste con su miseria material (DELIBES apud VILANOVA, 1993, p. 36). 
A pesar de un cierto pesimismo que parece invadir la obra, la preocupación del escritor con la naturaleza y la condición humana se suma a su gran inquietud con el futuro de la sociedad, de modo general. El escritor - "urbano hombre de campo" agudiza su mirada ante las precarias condiciones físicas y el degradante estado de muchos de sus personajes, pero también hacia el mundo que lo rodea.

La mirada sobre el hombre, el mundo y la historia en Miguel Delibes...podemos Ilamarla pesimista o decir, en todo caso, que es de un realismo que no ve motivos para esperar demasiado de la condición humana, ni del tinglado histórico-político, pero tampoco de la creación o la naturaleza tal y como es, porque en el más paradisíaco paisaje por el que atraviesa una perdiz con sus zapatos rojos, el narrador sabe muy bien que puede surgir un depredador, y se acabó el paraíso (LOZANO, 1993, pp. 22-23).

Con su hacer literario, preocupado por el bienestar de la persona humana, Miguel Delibes no deja que pase desapercibida la precariedad de cuestiones como salud e infraestructura, que afectan y afligen a la población rural. Como se puede observar con la descripción que hace el escritor de las características del tío Ratero, de inmediato se vislumbra su preocupación con el proceso de humanización del hombre del campo, desarrollada a través de una visión nutrida de la realidad latente: "El Ratero mostraba sus dientes podridos en una sonrisa ambigua, entre estúpida y socarrona" (DELIBES, 2010, p.11).

Ante esta descripción del tío Ratero, se puede visualizar la imagen que proyectan los habitantes del mundo rural, marcada por el abandono y la exclusión social que caracteriza la obra; personajes alejados del mundo del progreso, deformados por el hambre, convertidos en seres verdaderamente deplorables, contrarios a cualquier tipo de desarrollo, dada su falta de oportunidades $y / o$ posibilidades para cambiar su realidad.

Mientras el aparato del Estado funciona de forma precaria, el conocimiento del mundo exterior es privilegio de unos pocos, oriundos precisamente del mundo urbano. Representados por la figura del profesor, don Eustasio de la Piedra, o de Don Zósimo, el curón, este conocimiento no representa o favorece ningún tipo de cambio en la estructura social. En cambio, provoca el choque entre creencias, dada la intolerancia religiosa, justificada con una guerra sin fundamento, responsable de sembrar el rencor y el odio y, por consiguiente, la muerte: 
Era domingo y el Viejo Rabino apareció con su humilde traje de fiesta y sus zapatos apretados, y el Baltasar, el del Quirico, lo empujó con el cañón del mosquetón y le dijo: "Ahora voy a enseñarte yo dónde deben pastar las cabras". El Viejo Rabino parpadeaba y sólo dijo: "Qué quieres?". Y el Baltasar, el del quirico, dijo: "Que te vengas con nosotros". El Baltasar llevaba una cruz en el pecho y la Rabina miraba hacia ella como implorando, y luego miró para el viejo Rabino, que, a su vez, se miraba a los pies calzados con zapatos, y dijo humildemente: "Aguarda un momento". Al regresar de la alcoba vestía el traje de pastor y calzaba las alpargatas de goma y dijo: "Hasta luego". Después le dijo a Baltasar: "Cuando quieras".

Al día siguiente, el Antoliano encontró el cadáver en las Revueltas... (DELIBES, 2010, p.20).

La mirada delibiana hacia las circunstancias y consecuencias de la contienda, deseosa de poner fin a la intolerancia político-religiosa en la España de la postguerra, deja entrever su gran preocupación humanista. Como señala Lozano (1993), se permite ver lo que no se veía y oír lo que no se había oído: "desde llamar a las cosas por su nombre a asistir a esa especie de descomposición de cada personaje que al ser 'explicado' - como hace con los nombres - cada historia se convierte en una meditación o reflexión o alegoría ética."

Miguel Delibes es un incansable combatiente de todo lo que supone desigualdad e intolerancia político-religiosa y/o socio-económica; partidario de las libertades en su más amplia dimensión. El autor deja claro que no es posible que exista un equilibrio natural si las relaciones humanas carecen de entendimiento, si falta tolerancia; presenta la contradicción entre la teoría y la práctica religiosa, los contrastes entre el mundo rural y el mundo urbano, el progreso y el retraso; subraya lo efímera que es la vida humana y de la fragilidad de la existencia.

Las circunstancias en las que viven los personajes de Las Ratas son fruto de un proceso histórico desolador, de una guerra que sembró el sufrimiento, la miseria y el hambre en todo el país, además de solidificar un sistema totalitario, católico y retrógrado. En una sociedad rural, aislada en su propio mundo, los protagonistas son representados a través de características muy peculiares, por vía de rasgos que los individualiza; son seres oprimidos que no consiguen superar la pobreza, ni reaccionar ante la falta de perspectiva; individualizados e individualistas, y a la vez introspectivos e impotentes. No obstante, no se sienten derrotados y, a su manera, se sienten plenos; personajes que no disponen de las condiciones básicas de sobrevivencia, expuestos a las contradicciones de la sociedad. 
En este mundo sin oportunidades ni perspectivas, lo histórico queda como una realidad mítico-parabólica, perdido en el espacio y en el tiempo, ubicado como una referencia que sirve como motivación o entretenimiento en el presente. La referencia a la peste, igual que las corridas de toros, son presentados con la misma frialdad con la que pasa el tiempo. Estas referencias pasan a ser meramente anecdóticas, sin ejercer ninguna función más que retroceder en el espacio y en el tiempo. Con estas referencias, es mucho más fácil seguir adelante, sin caer en el desengaño; son un aliciente para las duras circunstancias, para esos tiempos de escasez, pero de disposición para continuar la búsqueda de víveres, para mantener la esperanza de vida, aunque ya se esté muerto para el mundo civilizado del consumo.

Se trata de un mundo apartado del progreso, donde el hecho de buscar el sustento se convierte en un verdadero arte, un arte que se perfecciona a partir de las adversidades, que exige un sobresfuerzo en la práctica cotidiana; una búsqueda destinada única y exclusivamente a la sobrevivencia, que se acerca, a veces, a lo instintivo, y parece cobrar, incluso, un carácter animalesco.

Automáticamente, el hombre del campo se refugia en su silencio, se cierra en su mundo; observa más de lo que habla, actúa más de lo que espera. En su mundo no hay lugar para el parasitismo; no hay lugar para esperar ni un día porque cada segundo de inactividad puede traer consecuencias fatales para la supervivencia. Hay que enfrentarse con las adversidades del tiempo como sea, hay que seguir cazando, persiguiendo las presas donde quiera que sea, y a la hora que sea; empezar desde muy pequeño a conocer y "controlar" el mundo en que vive como forma de ir superando los obstáculos y asegurando la supervivencia.

El drama de la pobreza en el campo se empieza a vivir muy pronto. Es ahí donde Delibes deja claro que no hay lugar para el parasitismo. No se puede confundir calamidad con conformidad, tampoco se le puede atribuir a la pereza la vida penosa de los protagonistas. Aun siendo niño, Nini es capacitado para enfrentarse a las adversidades de la vida; carga la experiencia dura de la lucha por la supervivencia, de la incertidumbre, del miedo; se expone al peligro al salir de caza con los mayores, lanzándose como un animal, a través de los sentidos, en búsqueda de las presas. Como subraya el propio Delibes, "el Nini es una especie de conciencia social," y añade: 
Con el Nini, intenté, por un lado, un contrapunto de la vida tremenda del medio rural castellano. Le di una elevación espiritual por encima del resto de los convecinos. Por otro lado, trato de simbolizar con él las dificultades que encuentra en un pueblo un ser inteligente para realizarse (DELIBES apud VILANOVA, 1993 p.37).

Lo paradójico es que en el mundo rural la miseria convive con la abundancia como si fuera ley de vida -; no hay preocupación con el bienestar colectivo; no hay movilidad social... es como si la propia naturaleza necesitara excluidos y excluyentes. En cierta manera, ésta es una lógica extendida y arraigada, que parece difícil de ser modificada. No hay compromiso con la educación, con la salud, con la infraestructura en general; lo cotidiano está marcado por una realidad llena de desafíos e incertidumbres, donde los problemas están a la orden del día, donde la vida y la muerte carecen de importancia; y surge la necesidad de migrar, forzada por las crudas circunstancias, cuando les gusta la vida del pueblo (DELIBES, 1971).

A pesar de los problemas socio-económicos en que viven las poblaciones del campo, Miguel Delibes nos muestra que la relación del hombre con la naturaleza ocurre de manera armoniosa, apegada. Dadas las circunstancias, los individuos acaban desarrollando una sensibilidad bastante significativa ante los acontecimientos presentes o futuros. A través de la convivencia y de la experiencia, aprenden a relacionar los hechos con los fenómenos naturales, desarrollando un conocimiento indispensable para la vida cotidiana; comprenden los fenómenos de su entorno a partir de la observación, de la asociación y de las manifestaciones del propio tiempo; aprenden a "predecir los días de sol, la llegada de las golondrinas y las heladas tardías" (DELIBES, 2010, p.28). Todo ello gracias al contacto diario, de toda una vida desarrollada en el mismo ambiente, sin interferencia de fenómenos exteriores que cambien la rutina de este mundo.

Las experiencias cotidianas del hombre rural, el conocimiento del entorno a través de la observación de las señales emitidas por la naturaleza, de fenómenos como el comportamiento de los pájaros, el color de las nubes o la fuerza del viento... representan también los sueños y las esperanzas del campesino. Desafortunadamente, también pueden predecir malos tiempos: heladas, sequías y demás manifestaciones negativas de la naturaleza. De todos modos, las catástrofes naturales no son vistas como una desgracia, sino como un anuncio previo de que 
hay que evitar el despilfarro, almacenando bien los víveres recogidos en la bonanza o cuidando mejor la naturaleza para que nunca deje de producir los alimentos.

Miguel Delibes subraya que la intuición goza de un prestigio especial en el mundo rural. Cada individuo interpreta y/o identifica los fenómenos ocurridos en el mismo ambiente de manera bastante diversificada. En el caso de Nini, desde muy temprano es considerado el profeta del campo debido a su agudizada percepción, observación e interpretación de las señales de la naturaleza: "el Nini ese todo lo sabe. Parece Dios" (DELIBES, 2010, p. 17).

La vida en el mundo rural está estrechamente ligada a la tierra. Sus habitantes son personas que dependen totalmente del medio ambiente para sacar el sustento y de ahí la necesidad de tener un conocimiento y previsión del tiempo meteorológico. Todo esto lejos de cualquier misticismo o dogmatismos, apenas observando las señales de la naturaleza y, a partir de allí sacando conclusiones que sirven de brújula para orientarse en el espacio y en el tiempo. No se trata de adivinanzas, ni de creer en lo increíble - ni se espera un futuro con "ríos de leche y miel"-, sino que son formas utilizadas como guías que favorecen la toma de decisiones, relacionadas con la práctica cotidiana, surgidas en función del día a día, a partir de su estrecha relación de dependencia con el entorno.

Miguel Delibes se desvincula completamente de un componente ideológicoromántico para referirse al mundo rural; adopta una postura literaria humanísticosocial, organizada por una visión ecologista, desconfiada del progreso y de todo lo que puede llevar a la destrucción de la naturaleza, y a la desaparición del mundo rural.

Para Delibes, el mantenimiento de las poblaciones rurales es algo sumamente positivo e indispensable para la vida del planeta. El escritor señala que la caza constante, dependiendo de su proporción, puede poner en riesgo de extinción algunas especies. Por otro lado, el mal uso de los recursos naturales, como la explotación aleatoria de la fauna y la flora, es otro blanco de crítica contundente por parte del ecologista.

La dependencia total de la caza de ratas - para el consumo propio - hace que el uso sostenible-racional de los recursos naturales sea una práctica desarrollada y respetada entre las poblaciones rurales estudiadas en esta obra. De esta manera, Miguel Delibes nos muestra que la preservación de la biodiversidad evita la 
degradación del medio ambiente, además de atender a los anhelos y necesidades del hombre del campo, ya que, en este caso, la ausencia de la sostenibilidad de la actividad de caza de ratas sería imposible asegurar el no desaparecimiento de estas comunidades, dada la falta de inversión, por parte del Estado, de políticas que aseguren el desarrollo de la vida con dignidad en el mundo rural.

Miguel Delibes demuestra su inconformidad, su preocupación y su indignación al notar que el mundo rural está condenado a vivir a merced de su propio destino; que muchas especies están en riesgo de extinción, y que la permanencia de las poblaciones rurales está sumamente comprometida, tal como también está comprometida la vida del planeta. Por otro lado, muestra la fragilidad e impotencia humanas ante las fuerzas naturales que, durante toda su vida les expone a las pérdidas y dolores, como es el caso de los daños ocasionados por las catástrofes naturales: las heladas, las sequía, etc.

Por medio de ejemplos impactantes, como el fenómeno de la sequía - y la consiguiente falta de agua y escasez de alimentos -, observamos que la narrativa delibiana provoca en el lector una indignación ante la problemática del abandono del mundo rural, expresando su inquietud y la necesidad de tomar partido ante las sórdidas circunstancias que, desde hace siglos, han condenado al abandono al sufrido hombre del campo, obligándolo a vivir "bajo un cielo inclemente, sobre una tierra inhóspita y baldía" (VILANOVA, 1991, p. 31)

En Las ratas, Miguel Delibes nos lleva a vivir de cerca las angustias del hombre rural, una vez que refleja toda su problemática, sus carencias, sus necesidades, pero, principalmente, la lucha diaria en búsqueda de la supervivencia. Para el escritor, el campesino está caracterizado como un hombre fuerte, luchador incansable, distante de ser un parásito del campo. No obstante, lleva a sus espaldas las circunstancias de las que son víctimas; padece las desgracias del retraso. Se trata de seres impregnados de valores y conocimientos propios, que les hacen peculiares e indispensables para el mantenimiento y el equilibrio de la vida del planeta.

Miguel Delibes observa y denuncia el sufrimiento de las poblaciones rurales que dependen de la lluvia para llevar a cabo su labor; muestra la desesperación del hombre del campo ante la impotencia de superar los obstáculos naturales y reclamar sus derechos ante los poderes públicos. Esta postura del escritor dista de presentar una visión idealizada del campo, sino que lo presenta como un universo |102| Revista Eletrônica Literatura e Autoritarismo, no 24 - julho a dezembro de 2014 - ISSN 1679-849X http://cascavel.ufsm.br/revistas/ojs-2.2.2/index.php/LA/index 
abundante de conflictos, de inestabilidad... donde confluyen el hambre y la miseria, la falta de perspectiva y la desconfianza en las promesas de cambio.

En Las ratas, el autor prescinde de pretender "civilizar" el mundo rural, de llevar un progreso que contribuya al abandono del campo, de acabar con las tradiciones de la vida campesina, sino que muestra las consecuencias de la falta de políticas públicas y sus drásticas consecuencias. Lo hace a través de la realidad de las poblaciones más pobres, protagonizada por Nini y el tío Ratero, víctimas de la degradación del medio ambiente, de la indiferencia social; condenados a la ignorancia, alejados de ser conscientes de sus derechos y deberes; convertidos en seres prescindibles para la cultura de las letras; animalizados y distanciados del mundo civilizado; indefensos ante las desgracias ocasionadas por el destino; imposibilitados de acceder a la dignidad humana, a la vida en abundancia.

En un escenario de incansable lucha por la supervivencia, Delibes llama la atención de las autoridades para los problemas existentes; refuerza la denuncia que hace constantemente de la inoperancia del sistema de gobierno vigente, reflejada en las circunstancias de vida de unas gentes que padecen "la tragedia de una tierra inhóspita y baldía, incapaz de sustentar a los hombres que la habitan, y, al propio tiempo", de un vivir dominados por un "fatalismo ancestral que les impide abandonar el lugar en donde nacieron" (VILANOVA, 1991, p. 36).

Los impactos sociales, causados por las catástrofes naturales, son una gran preocupación en la obra de Miguel Delibes. La eventual naturalidad de los fenómenos meteorológicos, y sus efectos inesperables e indeseables, provocan en el escritor una gran inquietud, lo que le lleva a adoptar esa actitud de preocupación y denuncia que caracteriza la obra.

La ausencia de las lluvias trae consecuencias sumamente negativas para las poblaciones rurales, compromete el futuro de las generaciones venideras y trae mucha inseguridad para los que dependen del campo para sacar el sustento. Por esta y otras razones, Miguel Delibes alza su voz en defensa de estas poblaciones que viven a merced de su propio destino, siempre preocupados con la posibilidad de la falta de agua, que provocan la desaparición y/o la escasez de los víveres que aseguran la supervivencia. Las incipientes propuestas de desarrollo para el campo son algo tan incierto como el propio destino de las poblaciones rurales. No hay una 
consistencia del proyecto de regadío, lo que nos permite concluir que la vulnerabilidad del mundo rural dista de tener un fin.

Muy preocupado por la posible desaparición de ciertas formas de vida, de cultura y de las tradiciones en general, Miguel Delibes, constantemente, está "al servicio de una reflexión sobre el hombre, la España y la Castilla de su tiempo" (REY, 1993, p.109). Para ello, utiliza expresiones propias de un mundo que le consagra como un hombre sencillo, un gran escritor ecologista, al tiempo que sus inquietudes determinan su vocación de escritor.

Miguel Delibes es consciente de la grotesca y sórdida realidad en la que viven los campesinos, alejados de toda posibilidad de cambio, condenados a tener sus vidas y sus tradiciones destruidas en nombre del progreso. Por ello, como lo subraya CARR (1993, p. 70), el escritor

\footnotetext{
hace una defensa de lo rural, como sinónimo de lo auténtico y perdurable, frente a los dogmas urbanos que dicta y proclama la sociedad de consumo. Delibes nos describe una sociedad con valores propios, sencillos, que están desapareciendo, por desgracia, del mapa social de España.
}

Las dramáticas circunstancias en las que viven las poblaciones rurales demuestran la urgente necesidad de cambio y de desarrollo local del campo. No basta sólo con conservar las viejas tradiciones y costumbres ancestrales, sino hacer con qué les llegue el progreso, vestido de dignidad e igualdad de oportunidades.

Y como reflejo de su preocupación con la fijación del hombre en el campo, Miguel Delibes se empeña en lograr unas condiciones de vida más dignas para las poblaciones rurales, implicándose en la lucha a favor de la justicia, lo que evitaría, indudablemente, el éxodo rural y la consiguiente despoblación del campo español; hace una defensa "casi elegíaca, del campesino y el campo castellanos, de un sistema de vida en trance de desaparición, de ese mundo que agoniza ante el que el autor lanza el S.O.S. de su mensaje humanista" (PALOMO, 1983, p. 163).

\section{REFERÊNCIAS}

CARR, Raymond. La sociedad española de posguerra en la novelística de Delibes. In: EL AUTOR Y SU OBRA: Miguel Delibes. Dirigido por José Jiménez Lozano. Actas del 
Escorial. Cursos de verano 1991. Universidad Complutense de Madrid, 1993, pp. 6971.

DELIBES, Miguel. Las ratas. Barcelona, Destino, 2010. . El camino. Barcelona, Destino, 2003.

DE LOS RÍOS, César Alfonso. Conversaciones con Miguel Delibes. Barcelona, Destino, 1993.

ELIZALDE, Ignacio. La actitud de Miguel Delibes ante la realidad. In: Miguel Delibes. El escritor, la obra y el lector. Dirigido por Cristóbal Cuevas García. Actas del V Congreso de Literatura Española Contemporánea, Universidad de Málaga, 12,13, 14 y 15 de noviembre de 1991. Editorial Anthropos.Barcelona, 1992, pp. 277-292. AMBITOS LITERARIOS/Ensayo.

LONG, M. L. La repercusión del conflicto del 36 en la obra de Miguel Delibes. Madrid, Pliegos, 2005.

LOZANO, José Jiménez. Lectura privada de Miguel Delibes. In: EL AUTOR Y SU OBRA: Miguel Delibes. Dirigido por José Jiménez Lozano. Actas del Escorial. Cursos de verano 1991. Universidad Complutense de Madrid, 1993, pp. 19-29.

NEBRERA, Gregorio Torres. "Arcadia amenazada": Modulaciones sobre un tema en la narrativa de Miguel Delibes. . In: Miguel Delibes. El escritor, la obra y el lector. Dirigido por Cristóbal Cuevas García. Actas del V Congreso de Literatura Española Contemporánea, Universidad de Málaga, 12,13, 14 y 15 de noviembre de 1991. Editorial Anthropos. Barcelona, 1992, pp. 31-60. AMBITOS LITERARIOS/Ensayo.

PALOMO, M. del Pilar. Estudios sobre Miguel Delibes. Madrid, Universidad Complutense, 1983.

REY, Alfonso. Tradición y originalidad en Delibes. In: EL AUTOR Y SU OBRA: Miguel Delibes. Dirigido por José Jiménez Lozano. Actas del Escorial. Cursos de verano 1991. Universidad Complutense de Madrid, 1993, pp. 101-109.

VILANOVA, Antonio. Inocencia natural y conciencia moral en la obra de Miguel Delibes. In: EL AUTOR Y SU OBRA: Miguel Delibes. Dirigido por José Jiménez Lozano. Actas del Escorial. Cursos de verano 1991. Universidad Complutense de Madrid, 1993, pp. 31-40. 